\title{
ANÁLISE DA MITIGAÇÃO DA REAÇÃO ÁLCALI-AGREGADO COM O TIPO DE CIMENTO
}

\author{
SANTANA, RAPHAEL ARLEGO DE ALCANTARA \\ Mestre em Engenharia Civil \\ Universidade Federal do Ceará \\ Ceará; Brasil \\ raphael_arlego@hotmail.com
}

\author{
Professor Doutor \\ Universidade Federal do Ceará \\ Ceará; Brasil \\ eduardo.cabral@ufc.br
}

CABRAL, ANTONIO EDUARDO BEZERRA

\author{
BRASILEIRO, FRANCISCA LILIAN CRUZ \\ Professora Mestre \\ Faculdade Ari de Sá (FAS) - GEMAD \\ Ceará; Brasil \\ lilian.brasileiro@outlook.com
}

\section{RESUMO}

Reação álcali-agregado (RAA) é uma preocupação corrente em obras submetidas a ambientes agressivos e a condições sucessivas de umidade, como pontes, blocos de fundações ou barragens. Uma das formas de mitigar esta reação, como mostram estudos anteriores, é com o uso de adições minerais em substituição de parte do cimento. Sendo assim, este trabalho tem por objetivo analisar a redução da expansão média oriunda da RAA utilizando cimentos com adição de pozolana e escória de alto-forno disponíveis no mercado de Fortaleza/CE, por meio da realização de ensaios padronizados na NBR 15577 (ABNT, 2018). Foram estudados cimentos com diferentes teores de adição destes materiais e diferentes tipos de adições pozolânicas. Os resultados indicam que há uma tendência de redução da expansão média com o aumento do teor de pozolana e escória no cimento, destacando os cimentos CP IV 32 RS e CP III 40 RS como os de melhor desempenho frente à RAA.

Palavras-chave: reação álcali- agregado, cimento com adição de pozolana, cimento com adição de escória de alto forno, mitigação.

\begin{abstract}
Alkali-aggregate reaction (AAR) is a common concern in projects subjected to aggressive environments and to successive humidity conditions such as bridges, foundation blocks or dams. One way to mitigate this reaction, as previous studies show, is using additions to replace part of the cement. Therefore, this work aims to analyze the reduction of the average expansion from the AAR due to the use of cements with addition of pozzolan and blast furnace slag available in the market of Fortaleza/CE by means of the accomplishment of standardized tests in ABNT NBR $15577 / 08$. The results indicate that there is a tendency of reduction of the average expansion with the increase of the pozzolanic and slag content on cement, highlighting the cements CP IV 32 RS and CP III 40 RS, both from Apodi, as the ones with the best performance against AAR.

Keywords: alkali-aggregate reaction, cement with pozzolanic addition, cement with addition of blast furnace slag, mitigation.
\end{abstract}

\section{INTRODUÇÃO}

A durabilidade do concreto está relacionada à maior ou menor capacidade deste resistir a agressões químicas, físicas, mecânicas e biológicas do ambiente para o qual foi projetado ou a interações deletérias internas do próprio concreto. Dentre as agressões químicas destacam-se os ataques por íons cloreto e sulfato, dióxido de carbono, ataques ácidos e as reações álcali-agregado (RAA) (CUNHA; CINCONTTO, 2008). 
A RAA é uma reação química que se processa, numa argamassa ou concreto, entre os íons hidroxilas $\left(\mathrm{OH}^{-}\right)$associados aos álcalis, óxido de sódio $\left(\mathrm{Na}_{2} \mathrm{O}\right)$ e óxido de potássio $\left(\mathrm{K}_{2} \mathrm{O}\right)$, provenientes do cimento ou de outras fontes, e agregados potencialmente reativos, em condições diferenciadas de temperatura, pressão e pH, na presença de água (FIGUERÔA; ANDRADE, 2008; PIRES, 2009). A Figura 1 ilustra este processo.

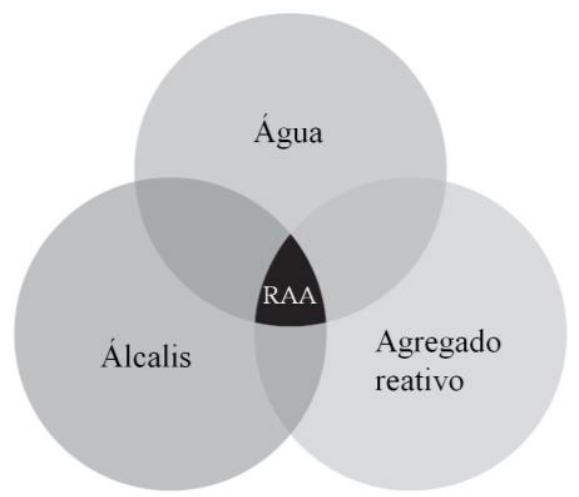

Figura 1 - Esquema da RAA (fonte: adaptado de Mehta e Monteiro, 2014).

Rolim (2010) lembra que álcalis são liberados no processo de hidratação do cimento, onde uma parcela destes fica disponível na solução dos poros do concreto. Além do cimento, ainda de acordo com o autor, outros materiais utilizados na produção do concreto, como água, aditivos e agregados que contenham minerais alcalinos podem ser considerados como fontes de álcalis na mistura.

Essa reação pode ou não resultar em um gel expansivo (dependendo da concentração de cal ou de álcalis) o qual ao se dispor nos vazios do concreto e na superfície do agregado em contato com a pasta de cimento pode resultar em fissuras generalizadas e desta forma comprometer a qualidade da estrutura (PAN et al., 2012).

Hasparyk (2005) lembra ainda que o sistema de fissuras gerado pela expansão do gel pode permitir o surgimento de outros mecanismos de deterioração, acelerando o processo de degradação e afetando de forma mais significativa a durabilidade do concreto, uma vez que o expõe às condições ambientais e à ação de agentes agressivos.

Valduga (2007) cita alguns dos sintomas ocorridos em estruturas de concreto em consequência da RAA: microfissuras no composto, principalmente na argamassa que preenche o espaço entre os agregados graúdos; fissuras na proximidade da superfície dos agregados graúdos, podendo também ocorrer na interface pasta/agregado; descolamento (perda de aderência) da argamassa junto à superfície dos agregados graúdos; possibilidade de ocorrência de bordas de reação ao redor dos agregados que reagiram com os álcalis; presença de gel exsudando ou preenchendo vazios no concreto; movimentação (abertura e/ou deslocamento relativo) de juntas de contração e de concretagem; fissuração característica na superfície, com panorama poligonal, havendo predominância na direção de maior dimensão.

Malvar et al. (2002) defendem que a medida mais eficiente para prevenir a RAA é o uso de agregado não reativo, solução nem sempre prática ou economicamente viável. Para o controle da reação, Silva (2007) diz que existem vários materiais disponíveis, e um meio de minimizar o seu risco é pela substituição parcial de cimento por adições. Segundo Mehta (2008), cerca de 50 a 70\% da massa de clínquer presente no cimento Portland pode ser substituída por diversos materiais complementares. Thomas et al. (2006) afirmam que produtos como pozolanas, escorias, cinzas volantes e misturas à base de sais de lítio podem ser usados para prevenir a reação, desde que sejam utilizados em quantidade correta.

Cachepa (2017) destaca a diminuição de teor de álcalis em cimentos e o emprego de pozolanas como adição mineral, tanto em cimentos como em concretos, como métodos de mitigação da RAA. Entretanto, conforme Hasparyk (1999), a depender de características como quantidade de fases reativas, teor de álcalis e finura da adição, o efeito inverso pode acontecer caso estas sejam utilizadas sem controle.

Munir et al. (2016) citam alguns materiais que podem ser utilizados para mitigação da RAA: escória granulada de altoforno, argila calcinada, cinzas volantes, cinza de casca de arroz, cinza de bagaço de cana e sílica ativa. Os teores mínimos dessas adições ao cimento Portland podem variar em função do grau de reatividade do agregado, do teor de 
álcalis no cimento, da qualidade desses materiais, bem como dos mecanismos de redução da expansão (MALVAR et al., 2002).

É muito importante determinar a reatividade do agregado antes deste ser usado no concreto e, a partir dessa avaliação, selecionar o cimento Portland mais adequado. No País são produzidos cimentos que além de clínquer e sulfato de cálcio, podem conter adições de fíler calcário, escória de alto-forno e materiais pozolânicos em diferentes teores. Quando o agregado é reativo e há disponibilidade de cimentos com escória ou materiais pozolânicos, a questão é saber se o teor presente é suficiente para mitigar a reação álcali-agregado (CUNHA; CINCONTTO, 2008).

Assim, o presente artigo pretende avaliar o potencial de mitigação da reação álcali-agregado dos cimentos com adições pozolânicas e de escória de alto-forno usados em obras da construção civil na cidade de Fortaleza/CE, por meio da realização de ensaio pelo método acelerado, conforme procedimentos estabelecidos na norma NBR 15577 (ABNT, 2018) em suas partes 4 e 5 .

\section{REVISÃO BIBLIOGRÁFICA}

Nos primórdios do conhecimento da reação álcali-agregado (RAA) acreditava-se que a limitação do teor de álcalis do cimento era suficiente para evitar o desenvolvimento da reação. Limitou-se dessa maneira o equivalente alcalino em $0,60 \%$. Posteriormente foi observado que apenas essa restrição não era suficiente, pois algumas obras executadas com cimento de equivalente alcalino inferior a 0,60\% apresentaram sinais da RAA (ROLIM, 2010). Pesquisas mostraram, então, que essa limitação no equivalente alcalino deveria ser associada ao uso de adições minerais para alcançar a eficácia necessária contra a RAA. Cunha e Cincontto (2008) afirmam que a eficiência das adições ativas em mitigar a RAA varia de acordo com sua composição química e mineralógica, proporção no cimento, grau de reatividade do agregado e com o tipo de reação.

As adições minerais, com base na sua ação físico-química, são geralmente classificadas em três grupos: material pozolânico, material cimentante e fíler. As adições contribuem na produção de materiais cimentícios com melhores características técnicas, pois modificam a estrutura interna da pasta de cimento hidratada, contribuindo para a diminuição do calor de hidratação (DAL MOLIN, 2011). Dos grupos mencionados, as pozolanas são as adições preferidas para a produção de concretos de maior durabilidade e na mitigação da RAA visto que é constituída de alumina, sílica e óxido de ferro, conforme a sua origem (CACHEPA, 2017).

O desempenho da atividade pozolânica, além de ser influenciado pela qualidade e quantidade de fases amorfas presente em sua estrutura, depende também de sua composição química e granulométrica, área superficial específica, textura (forma e tamanho do grão), densidade e relação a/c (MEHTA, 1987).

Munir et al. (2016) afirmam que a utilização da cinza volante em 30\% de substituição ao cimento é eficaz na redução das expansões devidas a RAA. Trindade (2011) estudou a adição da cinza da casca de arroz no concreto, sem nenhum tipo de beneficiamento. Ao utilizar o CP II Z adicionado de mais 20, 30 e 40\% de cinza volante para mitigação da RAA, as misturas se mostraram eficientes e seu efeito aumentou proporcionalmente ao aumento da adição de cinza volante, sendo classificadas como inócuas aos 16 e 30 dias. Já a mistura utilizando CP IV mostrou excelência em mitigar a reação expansiva, sendo classificada como inócua para as duas idades avaliadas.

Quando presente no cimento Portland em teores de $25 \%$ a $35 \%$, a cinza volante é uma pozolana eficiente na minimização da RAA. Também, escórias de alto-forno em teores acima de 50\%, sílica ativa, em teores de 10 a $12 \%$, e metacaulim, em teores próximos de $10 \%$ também têm sido relatados como eficientes na redução da reação (MALVAR et al., 2002).

Diferente das pozolanas, a escória forma produtos pela hidratação semelhantes ao do cimento, mesmo sem a presença de hidróxido de cálcio, entretanto, a velocidade das reações de hidratação das escórias de alto forno é muito lenta (TRINDADE, 2011). De acordo com Cachepa (2017), os principais compostos da escória granulada de alto-forno são a sílica, o óxido de cálcio, alumina, óxido de magnésio e óxido de ferro. Para Wapda (2004) o uso da escória entre 30 e $40 \%$ na substituição do cimento reduz a expansão da RAA e o calor de hidratação do cimento gerado no concreto massa.

Em estudo desenvolvido por Mizumoto e Salles (2012), todas as amostras de escória moídas indicaram o teor mínimo de $40 \%$ de adição para inibição da reação álcali-agregado. Munhoz (2007) verificou que, conforme o aumento do teor 
de adições de escória de alto-forno, cinza volante, metacaulim e de silica ativa, a expansão devido a RAA é reduzida, sendo que o teor mínimo necessário para mitigar as expansões é menor para a sílica ativa (em torno de 10\%), enquanto que para a escória seria em torno de 50\%. Para este autor, dentre os tipos de pozolanas estudados, a sílica ativa seria a mais eficiente na minimização dos efeitos da RAA, seguida pelo metacaulim e cinzas volantes.

Os teores mínimos para mitigar a expansão dos agregados analisados na pesquisa de Cunha e Cincontto (2008) foram: $10 \%$ de sílica ativa, $15 \%$, de metacaulim, $20 \%$ de cinza volante e $60 \%$ de escória de alto-forno. Os autores explicam que esse desempenho está provavelmente relacionado à composição química dos materiais e ao diâmetro das partículas, que conferem alta reatividade pozolânica, reduzem de forma acentuada o teor de hidróxido de cálcio da argamassa e favorecem a mitigação da RAA. No caso da escória de alto-forno, ainda segundo os autores, foram necessários maiores teores para reduzir a relação $\mathrm{CaO} / \mathrm{SiO}_{2}$ dos aglomerantes e o teor de $\mathrm{Ca}(\mathrm{OH})_{2}$ da argamassa após as reações de hidratação, atribuindo a menor eficiência dessa adição à sua composição química, cujo teor de cálcio é maior do que o de outras adições, sendo necessários teores de adição até seis vezes maiores que da sílica ativa para obter-se o mesmo grau de eficiência.

\section{MATERIAIS E MÉTODO}

\subsection{Materiais}

Aplicou-se, nesta pesquisa, cimentos com adição de pozolanas (cimento composto com pozolana CP II Z 32 e cimento pozolânico CP IV 32) e com adição de escórias (cimento composto com escória de alto-forno CP II E 32 e cimento de alto-forno CP III 32) comercializados no Brasil. As marcas de cimento utilizadas foram escolhidas por seu emprego nas obras de construção civil sujeitas a ambientes agressivos, como bases de geradores eólicos, em Fortaleza/CE, cidade onde este estudo foi realizado. A título de comparação, além destes cimentos, foi realizado um ensaio com o cimento padrão, cujas características estão estabelecidas na norma NBR 15577- 4 (ABNT, 2018).

Deste modo, foram usados os seguintes cimentos: Cimento Padrão (1); CP II E 32 RS da Marca X (2); CP III 40 RS da Marca X (3); CP II Z 32 RS da Marca X (4); CP IV 32 RS da Marca X (5); CP IV 32 RS da Marca Y (6) e CP IV 32 RS da Marca Z (7).

A fim de assegurar a ocorrência da reação álcali-agregado, como indicado na norma americana ASTM C441/C441M (2011), realizou-se a substituição do agregado natural por vidro temperado Duralex, uma vez que este material é composto, em sua maioria, por sílica. Para obtenção da granulometria definida na norma NBR 15577-4 (ABNT, 2018), o vidro foi colocado em uma máquina "Los Ángeles", com posterior separação das frações normativas com auxílio das peneiras de abertura 4,75;2,36;1,18;0,60;0,30 e 0,15 $\mathrm{mm}$ (Figura 2).

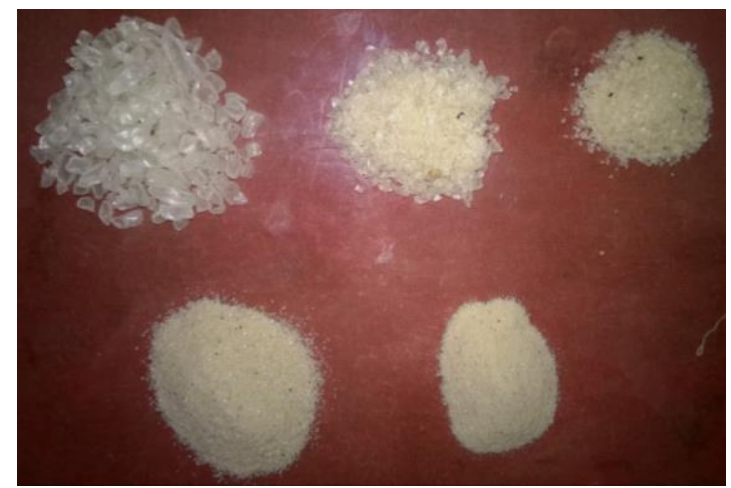

Figura 2 - Frações do vidro temperado Duralex usadas no ensaio.

\subsection{Método}

Uma vez que existem dois traços na ABNT NBR 15577-4 (ABNT, 2018) a serem usados de acordo com a massa específica do agregado, tendo como referência o valor de $2,45 \mathrm{~g} / \mathrm{cm}^{3}$, inicialmente, foi obtida a massa específica do vidro. Como as frações normativas podem ser classificadas como agregado miúdo, por estarem contidas no intervalo entre $4,75 \mathrm{~mm}$ e $75 \mu \mathrm{m}$, a massa específica foi obtida seguindo os procedimentos da norma DNER ME 194/98, obtendo-se o valor de $2,50 \mathrm{~g} / \mathrm{cm}^{3}$. Com isso, verificou-se qual dos traços deveria ser utilizado. Assim, na pesquisa, 
foram confeccionadas sete argamassas, uma para cada tipo de cimento, cujos traços seguem valores estabelecidos na NBR 15577-4 (ABNT, 2018), que é de 1: 2,25: 0,47 (cimento: agregado: água destilada) em massa.

$\mathrm{O}$ ensaio seguiu os procedimentos preconizados na norma supracitada para dosagem, mistura, moldagem, cura e medição de três corpos de prova por traço de argamassa, assim como para a preparação de solução, composta por hidróxido de sódio e água destilada mantida a $80^{\circ} \mathrm{C}$ em equipamento de banho-maria (Figura 3). As medições foram realizadas a cada 4 dias para um maior controle das expansões, sendo a última obtida aos 30 dias. $\mathrm{O}$ aparato utilizado para as medições foi um pórtico metálico com um relógio comparador com precisão de 0,001 mm (Figura 4).

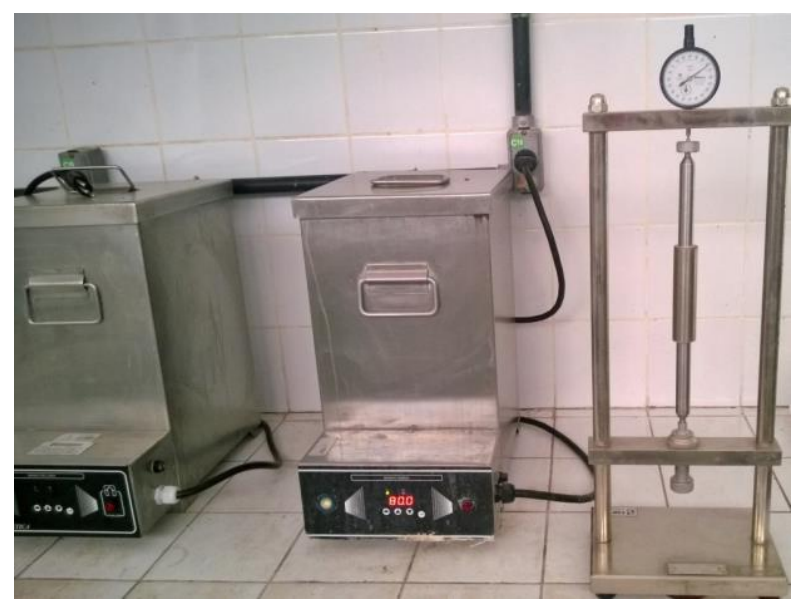

Figura 3 - Equipamento usado no ensaio.

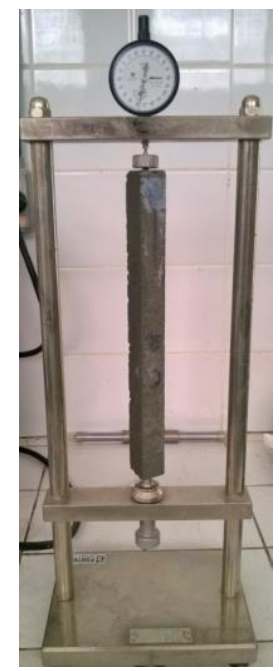

Figura 4 - Aparato sendo usado para medição.

Ao final de cada ensaio, os valores de expansão média foram comparados com os limites prescritos para verificação da mitigação da reatividade do agregado apresentados na parte 1 da NBR 15.577 (ABNT, 2018), conforme segue abaixo:

- Para expansões iguais ou superiores a $0,19 \%$ aos 30 dias, a reatividade é potencialmente deletéria e a mitigação com os materiais utilizados não é comprovada.

- Para expansões inferiores a $0,19 \%$ aos 30 dias, a reatividade é não deletéria e a mitigação com os materiais utilizados é comprovada.

Além disso, foi calculada a redução (R) da expansão média (em porcentagem) devido ao uso de materiais cimentícios mitigadores conforme a Equação 1, presente na ABNT NBR 15577-5 (ABNT, 2018), que relaciona os valores das expansões médias obtidas pelo método da parte 5 da norma (E5) com os valores obtidos pelo método com cimento padrão da parte 4 (E4) para verificar quanto de mitigação houve pelo uso do cimento com adição de pozolana. 


$$
\mathrm{R}=100 \times \frac{\mathrm{E} 4-\mathrm{E} 5}{\mathrm{E} 4}
$$

\section{RESULTADOS E DISCUSSÃO}

Os valores das expansões médias das barras produzidas com cada argamassa encontram-se apresentados na Tabela 1.

Tabela 1 - Resultados das expansões medidas nas barras das argamassas produzidas.

\begin{tabular}{|c|c|c|c|c|c|c|c|c|c|}
\hline \multirow{2}{*}{ Argamassas } & \multicolumn{9}{|c|}{ Expansão em \% na idade de } \\
& \multicolumn{9}{|c|}{ *valor obtido com auxílio do paquímetro } \\
\cline { 2 - 12 } & 1 dia & 4 dias & 8 dias & 12 dias & 16 dias & 20 dias & 24 dias & 28 dias & 30 dias \\
\hline 1 & 0,000 & 0,071 & $1,066^{*}$ & $1,353^{*}$ & $2,109^{*}$ & $2,570^{*}$ & $2,797^{*}$ & $2,971^{*}$ & $3,145^{*}$ \\
\hline 2 & 0,000 & 0,017 & 0,029 & 0,086 & 0,254 & 0,478 & 0,642 & $1,068^{*}$ & $1,235^{*}$ \\
\hline 3 & 0,000 & 0,002 & 0,007 & 0,020 & 0,039 & 0,063 & 0,072 & 0,126 & 0,160 \\
\hline 4 & 0,000 & 0,003 & 0,011 & 0,043 & 0,204 & 0,436 & 0,525 & 0,809 & 0,935 \\
\hline 5 & 0,000 & 0,001 & 0,004 & 0,011 & 0,030 & 0,042 & 0,053 & 0,069 & 0,078 \\
\hline 6 & 0,000 & 0,014 & 0,023 & 0,050 & 0,150 & 0,325 & 0,461 & 0,750 & 0,862 \\
\hline 7 & 0,000 & 0,003 & 0,022 & 0,047 & 0,251 & 0,590 & 0,708 & $1,210^{*}$ & $1,331^{*}$ \\
\hline
\end{tabular}

Algumas considerações sobre os ensaios com os cimentos 1, 2 e 7 são pertinentes. A partir de certa idade, os corpos de prova expandiram-se de forma tão intensa que ultrapassaram os limites de aferição do aparato exposto na Figura 4. Então, para concluir todas as medições até os 30 dias, utilizou-se a diferença entre medições feitas com o auxílio de um paquímetro de precisão igual a $0,05 \mathrm{~mm}$. No entanto, como nessas datas os valores de expansão médios já estavam bem superiores aos limites normativos, pode-se dizer que a reatividade é potencialmente deletéria e a mitigação com o vidro como agregado não é comprovada para tais amostras. Nas Figuras 5 e 6 pode-se observar os corpos de prova referentes à Argamassa 1, aquela com cimento padrão e, portanto, maior expansão. Já as Figuras 7 e 8 são referentes à Argamassa 5, produzida com cimento CP IV 32 RS da Marca X, que mitigou a reação álcali-agregado e obteve menor expansão dentre as estudadas. Pode-se comprovar a expressividade da reação por meio do padrão de fissuras em mapa.

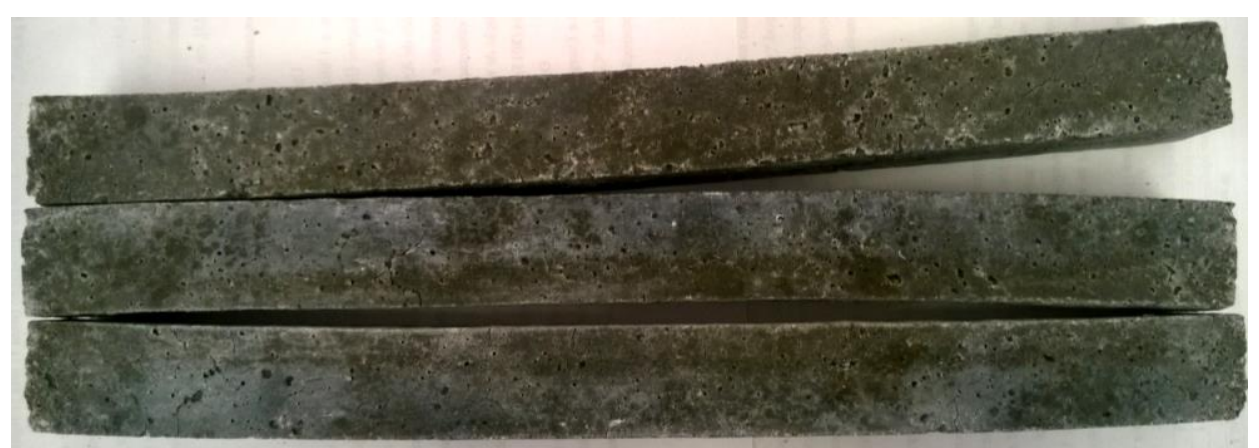

Figura 5 - Corpos de prova da argamassa 1 após 30 dias de ensaio (Cimento Padrão).

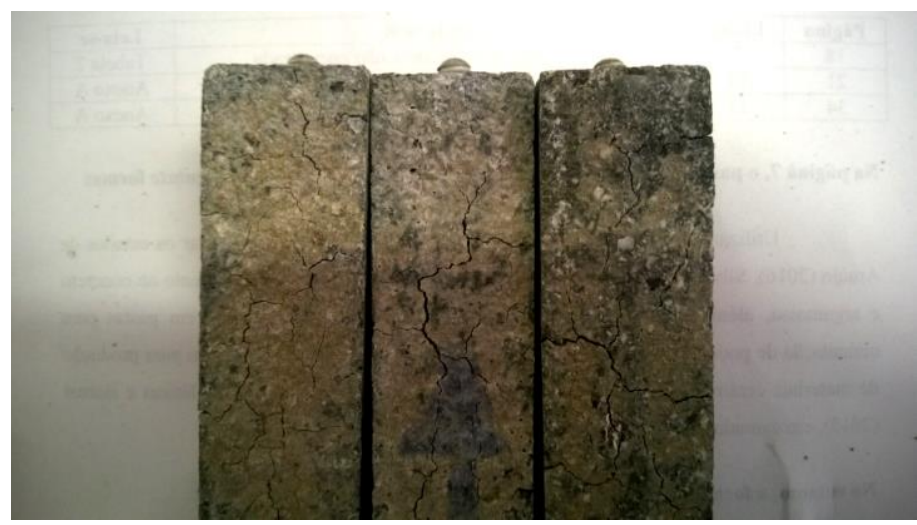

Figura 6 - Formação de fissuras nos corpos de prova da argamassa 1 após 30 dias de ensaio (Cimento Padrão). 
No caso extremo dos cimentos 1, 2, 4 e 7, a expansão foi tão grande que fez com que as barras envergassem. A Figura 5 ilustrou essa situação.

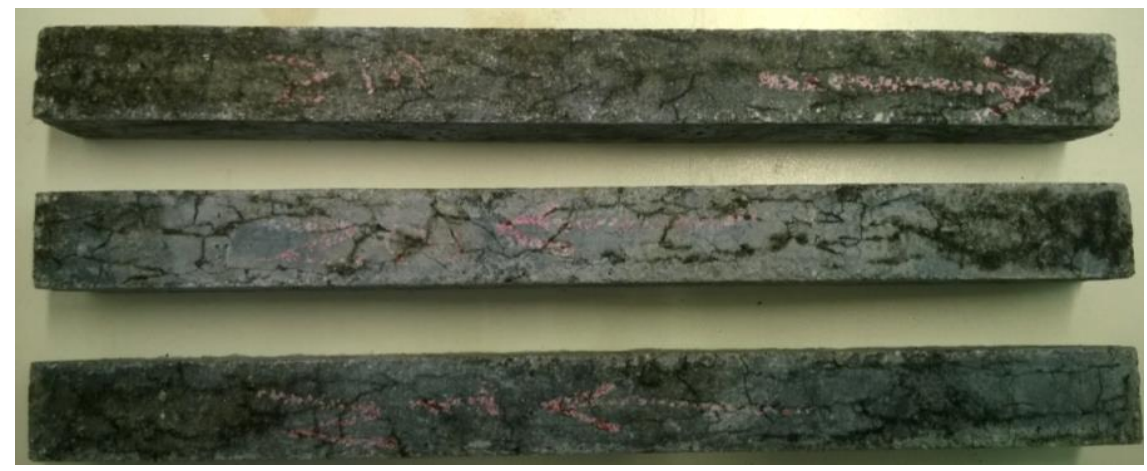

Figura 7 - Corpos de prova da argamassa 5 após 30 dias de ensaio (CP IV 32 RS - Marca X).

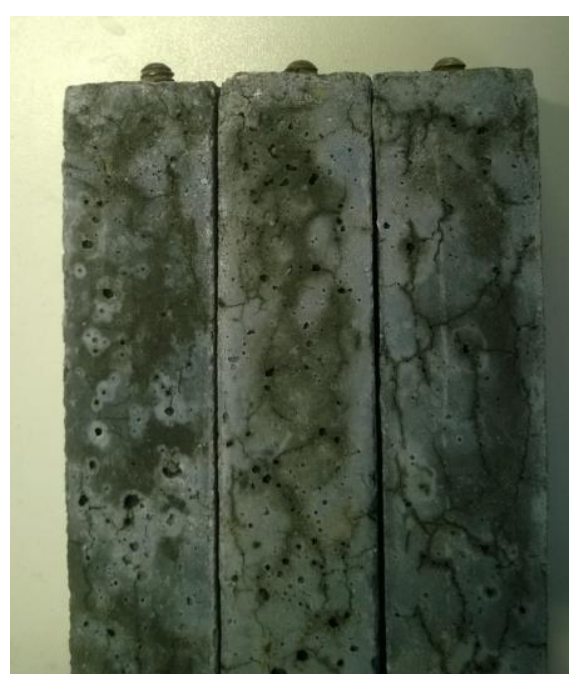

Figura 8 - Formação de fissuras nos corpos de prova da argamassa 5 após 30 dias de ensaio (CP IV 32 RS - Marca X).

A partir das expansões obtidas e dos limites estabelecidos nas normas, percebe-se que apenas os cimentos 3 e 5 mitigaram a reação, todos os demais resultaram em um sistema com expansão superior ao limite recomendado pela norma. Vale ressaltar que, apesar dos valores de expansão dos cimentos 3 e 5 estarem próximos aos 16 dias, os resultados do cimento 3 são quase que o dobro da expansão do cimento 5 aos 30 dias. A Figura 9 ilustra esse comportamento, bem como o dos demais ensaios.

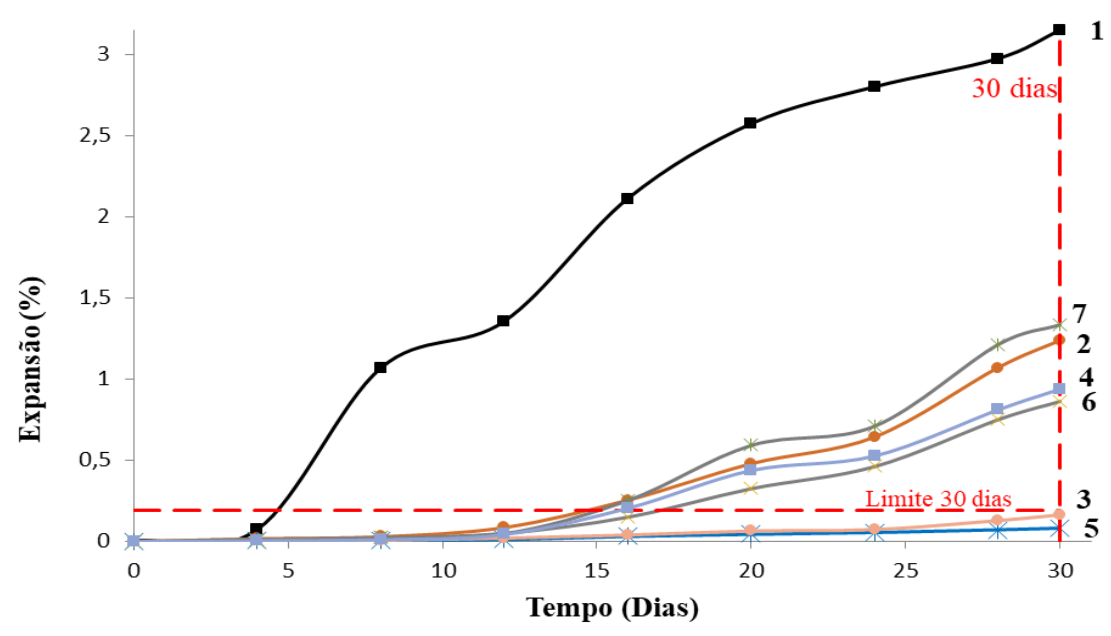

Figura 9 - Expansão das barras com o tempo. 
Para uma melhor visualização dos resultados, eliminou-se a representação dos dados do cimento padrão, gerando a Figura 10.

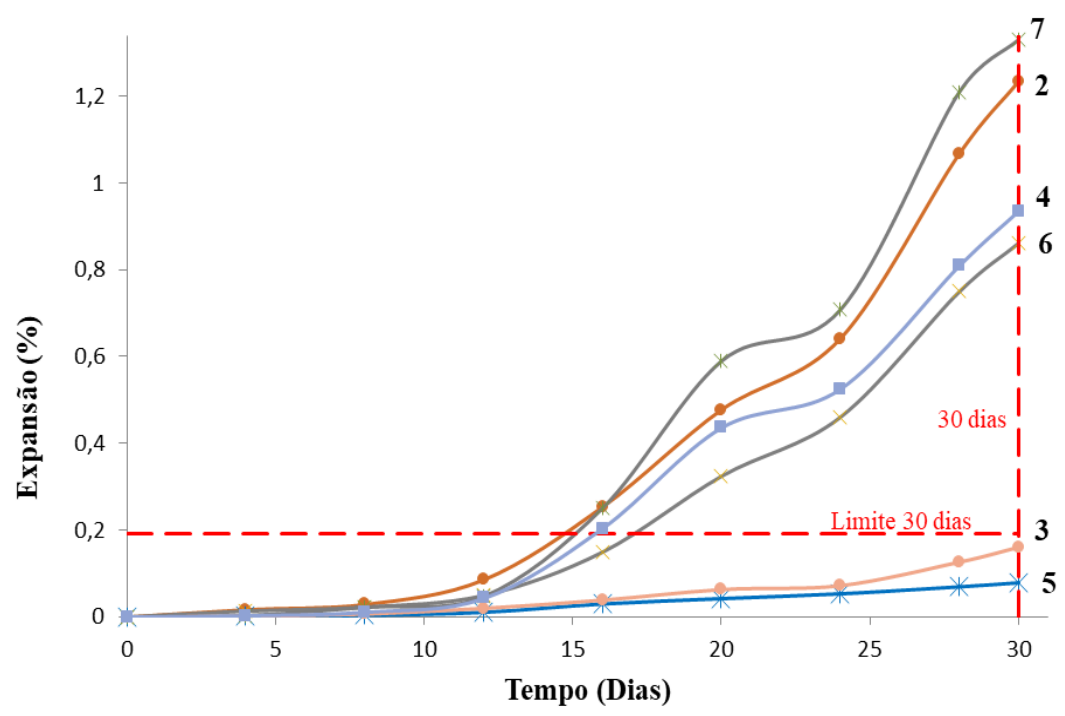

Figura 10 - Expansão das barras com o tempo.

Como pode ser observado, a adição de pozolana, no caso, já presente na composição dos cimentos, à semelhança do que notou Shayan (1989), mitiga em algum grau a expansão devido à RAA. Constatação semelhante foi feita com os resultados dos cimentos com escória de alto-forno, conforme já observado por Malvar et al. (2002). Dos cimentos testados, os únicos que se mantiveram abaixo dos limites normativos, mesmo aos 30 dias, foram os cimento 3 e 5, sendo este último o que menos expandiu. Utilizando a Equação 1, foi calculada a redução da expansão média em relação ao cimento padrão para todos os cimentos em questão aos 30 dias e os resultados podem ser vistos na Tabela 2.

Tabela 2 - Redução da expansão média em relação ao cimento padrão (30 dias).

\begin{tabular}{|c|c|c|c|c|c|c|}
\cline { 2 - 7 } \multicolumn{1}{c|}{} & \multicolumn{5}{c|}{ Cimento } \\
\cline { 2 - 7 } \multicolumn{1}{c|}{} & 7 & 2 & 4 & 6 & 3 & 5 \\
\hline Redução (\%) & 57,68 & 60,73 & 70,27 & 72,59 & 94,91 & 97,52 \\
\hline
\end{tabular}

Tais diferenças podem ser explicadas pelo teor de pozolana adicionado no cimento, cujos valores foram fornecidos pelas fabricantes e dispostos na Tabela 3, e pelo teor de escória, apresentado na Tabela 4. Nota-se que os cimentos CP IV tiveram melhores resultados frente ao CP II Z, pois têm maior teor pozolânico. Tendência que se repediu para os cimentos CP II E e CP III. De acordo com a NBR 16697 (ABNT, 2018), um cimento do tipo CP II Z deve conter uma massa de material pozolânico seco entre $6 \%$ e $14 \%$ e o CP IV $15 \%$ e $50 \%$, já o CP II E deve conter de $6 \%$ a $34 \%$ de escória de alto-forno e o CP III de $35 \%$ a $70 \%$.

Outro ponto que pode justificar o melhor desempenho dos cimentos CP IV é o resultado obtido por Lucca (2010), que verificou que uma substituição de $15 \%$ da massa de cimento já é suficiente para reduzir os efeitos da expansão para os limites preconizados na NBR 15577-1 (ABNT, 2018). Wapda (2004) mostrou que é necessário de 30 a $40 \%$ de substituição do cimento pela escória para reduzir a expansão da RAA, logo, os cimentos CP III possuem melhor desempenho na mitigação da RAA frente aos cimentos do tipo CP II E. Ratificando o que disse Cachepa (2017), as pozolanas parecem mitigar de forma mais eficiente a RAA.

Tabela 3 - Porcentagem de pozolana adicionada ao cimento.

\begin{tabular}{|c|c|c|c|c|}
\cline { 2 - 5 } \multicolumn{1}{c|}{} & \multicolumn{4}{c|}{ Cimento } \\
\cline { 2 - 5 } & 4 & 5 & 6 & 7 \\
\hline Pozolana (\%) & 14 & 30 & 20 & 35 \\
\hline
\end{tabular}


Tabela 4 - Porcentagem de escória de alto-forno adicionada ao cimento.

\begin{tabular}{|c|c|c|}
\cline { 2 - 3 } \multicolumn{1}{c|}{} & \multicolumn{2}{c|}{ Cimento } \\
\cline { 2 - 3 } \multicolumn{1}{c|}{} & 2 & 3 \\
\hline Escória (\%) & 34 & 50 \\
\hline
\end{tabular}

Ao aplicar o coeficiente de correlação de Pearson nas variáveis "redução da expansão" e "teor de pozolana", encontrase o valor de 0,80, o que, de acordo com Hinkle, Wiersma e Jurs (2003 apud MUKAKA, 2012), por estar entre 0,7 e 0,9 , mostra uma forte correlação positiva, o que significa que, na medida em que uma aumenta, a outra tem uma forte tendência em aumentar.

Aplicando o mesmo coeficiente para o teor de escória de alto-forno, tem-se o valor de 0,97, o que indicaria, segundo os mesmos autores, uma correlação positiva muito forte. No entanto, para melhor avaliar a existência dessa correlação, deve-se realizar o ensaio com mais cimentos com diferentes teores. Apesar do cimento 7 apresentar maior quantidade de pozolana, o cimento 5 pode ter apresentado uma maior mitigação pelo fato de ser o único, dentre os cimentos pozolânicos avaliados, que emprega a cinza volante como material pozolânico, enquanto que os demais utilizam pozolanas naturais.

\section{CONSIDERAÇÕES FINAIS}

Conforme os resultados obtidos, pode-se concluir que os cimentos com adições pozolânicas e de escória de alto-forno têm a capacidade de reduzir em algum grau a expansão média devido à reação álcali-agregado que ocorre com o vidro. Tal mitigação parece aumentar conforme se aumenta o teor de adição com relação à massa de aglomerante, uma vez que os cimentos CP IV e CP III obtiveram reduções superiores as dos CP II Z e CP II E. Ademais, há uma forte correlação positiva entre a redução da expansão e o teor de pozolana adicionada ao cimento. Mais ensaios devem ser feitos com os cimentos com escória para que uma correlação mais confiável seja feita.

Outra constatação foi que os resultados mostram indícios de que o tipo de pozolana tem influência na mitigação da RAA, sendo necessários estudos mais aprofundados para ratificar tal observação. Além disso, os cimentos pozolânicos parecem ter um melhor desempenho na mitigação da RAA quando comparado com os cimentos com escória de altoforno.

Os melhores desempenhos na mitigação da RAA ocorreram com os cimentos 5 e 3 , respectivamente, um cimento pozolânico com cinza volante e um cimento de alto-forno. Tais cimentos se mantiveram abaixo dos limites normativos para expansão das barras no ensaio acelerado, mesmo utilizando um agregado altamente reativo, após 30 dias.

As limitações do trabalho foram relativas ao crescimento exacerbado de algumas amostras, que impediram a aferição da expansão ao longo de todo o curso dos 30 dias usando o aparato normativo, tendo que ser medido com o auxílio de um paquímetro.

Como trabalhos futuros, sugere-se repetir os ensaios dos cimentos com adições de escória (CP II E 32 e CP III 32 ) incluindo mais cimentos com outros teores de adição. Além disso, propõe-se que sejam feitos ensaios que durem mais tempo, como a parte 6 da NBR 15.577 (ABNT, 2018), para que se possa ter uma melhor avaliação do comportamento de tais cimentos em volumes maiores de concreto.

\section{AGRADECIMENTOS}

Os autores são gratos aos funcionários do Laboratório de Materiais de Construção Civil da UFC, pela ajuda no beneficiamento dos vidros utilizados, e à empresa Companhia Industrial de Cimento Apodi, por financiar a pesquisa. $\mathrm{O}$ autor três também agradece ao apoio da Fundação Cearense de Apoio ao Desenvolvimento Científico e Tecnológico (Funcap).

\section{REFERÊNCIAS}

ABNT - Associação Brasileira de Normas Técnicas. NBR 16697. Cimento Portland: Requisitos. Rio de Janeiro, 2018.

NBR 15577-1: Agregados - Reatividade álcali-agregado - Parte 1: Guia para avaliação da reatividade potencial e medidas preventivas para uso de agregados em concreto. Rio de Janeiro, 2018. 
. NBR 15577-4. Agregados - Reatividade álcali-agregado - Parte 4: Determinação da expansão em barras de argamassa pelo método acelerado. Rio de Janeiro, 2018.

NBR 15577-5. Agregados - Reatividade álcali-agregado. Parte 5: Determinação da mitigação da expansão em barras de argamassa pelo método acelerado. Rio de Janeiro, 2018.

. NBR 15577-6. Agregados - Reatividade álcali-agregado. Parte 6: Determinação da expansão em prismas de concreto. Rio de Janeiro, 2018.

ASTM - American Society for Testing and Materials. C441 / C441M-11. Standard Test Method for Effectiveness of Pozzolans or Ground Blast-Furnace Slag in Preventing Excessive Expansion of Concrete Due to the Alkali-Silica Reaction, ASTM International, West Conshohocken, PA, 2011.

CACHEPA, M. M. Mitigação da reação álcali-agregado em concreto com o emprego de resíduo de cerâmica vermelha e metacaulim. Programa de Pós-Graduação em Engenharia Civil. Dissertação de Mestrado. Universidade do Vale do Rio dos Sinos. São Leopoldo, 2017.

CSA - Canadian Standards Association. A23.2-26A: Test methods and standard practices for concrete - Determination of potential alkali-carbonate reactivity of quarried carbonate rocks by chemical composition. Ontario, Canadá, 2014 (Reprinted September 2015).

CUNHA, F. A.; CINCONTTO, M. A. Efeito de adições ativas na mitigação das reações álcali-sílica e álcali-silicato. Boletim Técnico da Escola Politécnica da USP. Departamento de Engenharia de Construção Civil. São Paulo: EPUSP, 2008.

DAL MOLIN, D. C. C. Adições minerais para concreto estrutural. In: ISAIA, G. C. Concreto: ensino, pesquisa e realização, v. 1, p. 345-378. São Paulo: IBRACON, 2011.

DNER - Departamento nacional de estradas de rodagem ME 194. Agregados - determinação da massa específica de agregados miúdos por meio do frasco Chapman. Rio de Janeiro, 1998.

FIGUERÔA, J. P.; ANDRADE, T. O ataque da Reação Álcali - Agregado sobre as estruturas de Concreto: a descoberta pioneira da ocorrência do problema em fundações de pontes e edifícios na Região Metropolitana do Recife - Recife:

Ed. Universitária da UFPE, 2007.

HASPARYK, N. P. Investigação de concretos afetados pela reação álcali-agregado e caracterização avançada do gel exsudado. Programa de Pós-Graduação em Engenharia Civil. Tese de Doutorado. Universidade Federal do Rio Grande do Sul. Porto Alegre, 2005.

HASPARYK, N. P. Investigação dos mecanismos da reação álcaliagregado - efeito da cinza de casca de arroz e da sílica ativa. Escola de Engenharia Civil. Dissertação de Mestrado. Universidade Federal de Goiás. Goiânia, 1999.

LUCCA, A. C. K. Reação álcali-agregado: efeito do uso de cinza volante. 2010. 97 f. Projeto de graduação (Engenharia Civil) - Universidade Federal do Rio Grande do Sul. Porto Alegre, 2010.

MALVAR, L. J.; CLINE, G. D.; BURKE, D. F.; ROLlingS, R.; SHERMAN, T. W.; GREENE, J. L. Alkali-Silica Reaction Mitigation: state of the art and recommendations. ACI Materials Journal, v. 99, n. 5, p. 480-489, 2002.

MEHTA, P. K. Concreto Sustentável. Revista Téchne, 139. São Paulo: Pini, 2008.

MEHTA, P. K. Natural pozzolans: Supplementary cementing materials. Prox., Int. Symp. On advances in Concrete Tecnology, V. M. Malhotra, ed., CANMET, Athens, Greece, p. 407-430, 1987.

MEHTA, P. K.; MONTEIRO, P. J. Concreto: Microestrutura, Propriedades e Materiais. São Paulo: Editora Nicole Pagan Hasparyk, 2. ed., 2014.

MIZUMOTO, C.; SALLES, F. M. Efeitos da aplicação de escória granulada de alto forno em diferentes finuras em composições de argamassa. Anais do 54 Congresso Brasileiro do Concreto. Maceió, 2012. 
MUKAKA, M. M. Statistics Corner: A guide to appropriate use of Correlation coefficient in medical research. Malawi Medical Journal, v. 24, n. 3, p. 69-71, 2012.

MUNHOZ, F. A. C. Efeito de adições ativas na mitigação das reações álcali-sílica e álcali-silicato. Departamento de Engenharia de Construção Civil. Dissertação de Mestrado. Escola Politécnica da Universidade de São Paulo. São Paulo, 2007.

MUNIR, M. J.; QAZI, A. U.; KAZMI, S. M. S.; KITHAB, A.; ASHIQ, S. Z.; AHMED, I. Literature review on alkali silica reactivity of concrete in Pakistan. Pakistan Journal of Science, v. 68, n. 01, p. 53-62, 2016.

PAN, J. W.; FENG, Y. T.; WANG, J. T.; SUN, Q. C.; ZHANG, C. H.; OWEN, D. R. J. Modeling of alkali-silica reaction in concrete: a review. Frontiers of Structural and Civil Engineering, v. 6, n. 1, p.1-18, 2012.

PIRES, K. O. Investigação do Potencial Reativo Álcali-Agregado Residual - Um estudo de Caso. Programa de PósGraduação em Construção Civil. Dissertação de Mestrado. Universidade Federal do Paraná. Curitiba, 2009.

ROLIM, P. H. B. Reação álcali-agregado: avaliação do método químico de ensaio. Programa de Pós-Graduação em Engenharia Civil. Dissertação de Mestrado. Universidade Federal de Santa Catarina. Florianópolis, 2010.

SHAYAN, A. Re-examination of AAR in an old concrete. Cement and concrete research. v. 19, n. 3, p. 434-442, 1989.

SILVA, P. N. Reação Álcali-Agregado nas Usinas Hidrelétricas do Complexo Paulo Afonso/CHESF. - Influência da Reação nas Propriedades do Concreto. Programa de Pós-Graduação em Engenharia de Construção Civil. Dissertação de Mestrado. Escola Politécnica da Universidade de São Paulo. São Paulo, 2007.

SILVEIRA, A. A. Contribuição ao estudo do efeito da incorporação de cinza de casca de arroz em concretos submetidos à reação álcali-agregado. Programa de Pós-Graduação em Engenharia Civil. Tese de Doutorado. Universidade Federal do Rio Grande do Sul. Porto Alegre, 2007.

THOMAS, M.; FOURNIER, B.; FOLLIARD, K.; IDEKER, J.; SHEHATA, M. Test Methods for Evaluating Preventive Measures for Controlling Expansion due to Alkali-Silica Reaction in Concrete. The University of Texas as Austin. Austin, 2006.

TRINDADE, G. H. Durabilidade do concreto com cinza de casca de arroz natural sem moagem: mitigação da reação álcali-sílica e penetração de cloretos. Programa de Pós-Graduação em Engenharia Civil. Dissertação de Mestrado. Universidade Federal Santa Maria. Santa Maria, 2011.

VALDUGA, L. Influência das Condições de Ensaio da ASTM C 1260 na Verificação da Reação Álcali-Agregado. Programa de Pós-Graduação em Engenharia Civil. Tese de Doutorado. Universidade Federal do Rio Grande do Sul. Porto Alegre, 2007.

WAPDA. Study Report-Concrete Materials Studies, Mangla Dam Raising Project, 2004. 